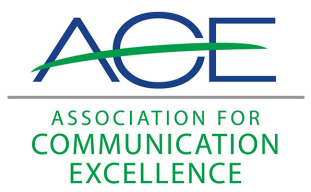

Journal of Applied Communications

\title{
Why Trades Get No Respect; Defending the Editorial Budget; What's Really Happening in the Job Market; Marketing is Everything; The Scientific Poster: Guidelines for Effective Visual Communication; Editing and Publication: A Training Manual
}

Kurt Knebusch

Ken Kingsley

Carol Sanders Reiner

See next page for additional authors

Follow this and additional works at: https://newprairiepress.org/jac

(c) (1)(2)

This work is licensed under a Creative Commons Attribution-Noncommercial-Share Alike 4.0 License.

Recommended Citation

Knebusch, Kurt; Kingsley, Ken; Reiner, Carol Sanders; and Kern, K. Robert (1991) "Why Trades Get No Respect; Defending the Editorial Budget; What's Really Happening in the Job Market; Marketing is Everything; The Scientific Poster: Guidelines for Effective Visual Communication; Editing and Publication: A Training Manual," Journal of Applied Communications: Vol. 75: Iss. 2. https://doi.org/10.4148/ 1051-0834.1504

This Review is brought to you for free and open access by New Prairie Press. It has been accepted for inclusion in Journal of Applied Communications by an authorized administrator of New Prairie Press. For more information, please contact cads@k-state.edu. 


\title{
Why Trades Get No Respect; Defending the Editorial Budget; What's Really Happening in the Job Market; Marketing is Everything; The Scientific Poster: Guidelines for Effective Visual Communication; Editing and Publication: A Training Manual
}

\author{
Abstract \\ Reviews of "Why Trades Get No Respect," by Richard M.O'Connor; "Defending the Editorial Budget," by \\ Frank Finn; "What's Really Happening in the Job Market," by Kathryn Kane; "Marketing is Everything," by \\ Regis McKenna; "The Scientific Poster," by Diane L. Matthews; "Editing and Publication: A Training \\ Manual," by lan Montagnes. \\ Authors \\ Kurt Knebusch, Ken Kingsley, Carol Sanders Reiner, and K. Robert Kern
}


Knebusch et al.: Why Trades Get No Respect; Defending the Editorial Budget; What

"Why Trades Get No Respect," by Richard M. O'Connor in Folio: (August 1991), The Hanson Publishing Group Inc., Stamford, Connecticut, pp. 79-81. (Folio: is published once a month by Hanson Publishing, 6 River Bend, Stamford, Connecticut 06907 0949. Call 203/358-9900 to subscribe or to get past issues.)

Is your magazine boring and bland, or bright and biting? Richard $\mathrm{M}$. O'Connor, editor-in-chief and publisher of Successful Meetings tells you why so many trade magazines are mediocre - and how they can change. What he says might apply to college of agriculture or other institutional magazines as well: namely, that "too many trade editors think that all they have to do is serve their industry and compete against [other trades]."

To that he says baloney.

Why? Because trade publications, like all publications, compete for a reader's time. Today's readers, O'Connor explains, lack the time to go through all the magazines they get. So he offers this counsel: "If you want your book to be noticed, to grab a reader's attention and sustain that reader's loyalty, it must look and read as good as a top consumer book. Anything else is unacceptable."

The basics of his advice are: Avoid complacency; boost quality; dramatize what's inside with "cleaner, bolder, more dramatic" layouts; pursue lively, provocative stories; and compel readers to grab your magazine by always employing enticing covers.

Covers from Successful Meetings from before and after O'Connor took charge help illustrate the article. The contrast and the newsstand look he installed are clear.

O'Connor rails that many editors don't give their magazines a point of view because they fear antagonizing advertisers (administrators, perhaps, for ACE members). But he believes our job is to report and interpret the news - intelligently, fairly, yes, but also at the expense, sometimes, of advertisers. You'll risk angering some bigwigs, he implies, but your readers will respect your editorial integrity, and that boosts the validity of your magazine.

Brave words for ACE members with grumpy higher-ups. If nothing else, though, those words can spur a closer look at what we produce and why.

Kurt Knebusch

Ohio State University-Wooster

\section{"Defending the Editorial Budget," by Frank Finn in Folio:, (July 1991), The Hanson Publishing Group Inc., Stamford, Connecticut, pp. 79-81.}

The college budget tightens, and your magazine ends up thin, shabby - or history. Don't let this happen to you, says publishing consultant Frank Finn. Defend your showpiece by stressing the benefits of maintaining editorial quality. Finn, president of Creekside Communications, a consulting company in Arlington, Virginia, details key tactics:

- Figure the minimum amount of money you need to do your job soyou gain credibility as a like-minded fat-trimmer. 


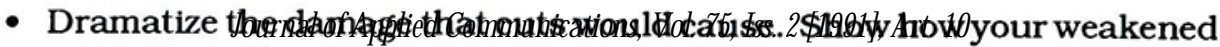
magazine will suffer next to the competition.

- Promote the value of quality. Score points, Finn says, by citing evidence of reader appreciation of your work.

- And several more maneuvers, including finding production efficiencies, that can save your end (of the budget).

Most ACE-type magazines don't generate income through advertising or subscriptions. So often our case for quality lacks an obvious bottom line. Finn's tactics can help.

An aggressive defense might be work well-spent. As Finn concludes, "Waging this campaign can consume untold hours. But is there a better use of your time than protecting the quality of your magazine?"

Kurt Knebusch

Ohio State University-Wooster

"What's Really Happening in the Job Market," by Kathryn Kane in IABC Communication World, (August 1991), International Association of Business Communicators, San Francisco, California, pp. 26-29. (IABC Communication World is published monthly, except June/July, by the International Association of Business Communicators. Nonmember library or educational institution subscriptions are $\$ \mathbf{4 8}$. For more information, call (800) PRO-IABC (in the United States and Canada) or (415) 4333400 (outside of North America).

Your funding drops. Your salary is slashed. You get fired. Tight state budgets, college restructuring, even desktop publishing are some of the factors costing you your operating budget, take-home pay - or job. To find out who's most affected by communication cuts (and how you can protect yourself), Kathryn Kane, a vice president for client services with L.C. Williams \& Associates, conducted a panel discussion with members of the International Association of Business Communicators. Their thoughts ranged from angry to optimistic - most translate to what ACE members face, too.

Underlying the discussion, Kane writes, was "a new recognition that the rules of the game have changed, that careers must be managed to allow for reversals as well as successes."

Among the advice (some of it obvious): Always have your resume ready. Watch for organizational warning signs. "Be prepared - even assume you'll be laid off." And call on your relationships in IABC (and ACE and more) to help you through trouble. "Your overall strategy," one panel member said, "should be to control your own destiny."

A key question to the group was "How Can IABC Help?," an issue that parallels President Dave King's concern about how ACE can help communicators "survive and prosper" (July/August 1991 Signals newsletter). One panel member cites managers who "are more aware of the communications component of management, and are becoming good communicators - or https://newprairiepress.org/jac/vol75/iss2/10

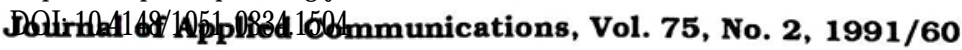


think they are." King tells of a smug agricultural engineer/publisher armed only with a computer and laser printer.

Such cases will be faced more often, one panel member says. But that's where professional groups come in, the discussion implies. Says another member in closing comments: "IABC can look to the future for members five to 10 years down the road - and get them geared up for it. Get them ready for the employment trends, the impact of technology, the threats and opportunities. That can be our greatest service."

Read the entire article if you think ACE should plan likewise.

Kurt Knebusch

Ohio State University-Wooster

\section{"Marketing Is Everything," by Regis McKenna in Harvard Business Review, (January-February 1991); Vol. 69, No. 1. Harvard Business School: Boston, MA; pp. 65-79.}

The author's premise, though not clearly conveyed in his title, is that technology is changing the face of marketing. It's allowing businesses and organizations to customize products to the specifications of customers. And it's enabling marketers to develop and test marketing plans based on solid, specific consumer data.

McKenna contends that the '90s will belong to the customer, "and that is great news for the marketer." He says that technology is transforming choice, and choice is transforming the marketplace. McKenna explains how traditional marketing (slow and unresponsive) is being replaced by what he calls "knowledge-based and experienced-based marketing." Much of the article describes this "new marketing" and helps the reader identify its characteristics.

Extension Service readers involved in program development and/or program marketing might take special note of McKenna's emphasis on the customer (client). He says that exploding choice and unpredictable change make for fierce competition for the customer. The answer, he contends, is not more marketing but better marketing. In McKenna's words, "that means marketing that finds a way to integrate the customer into the company, to create and sustain a relationship between the company and the customer.

"Marketing today is not a function; it is a way of doing business," he continues. "Marketing has to be all-pervasive, part of everyone's job description, from the receptionist to the board of directors (administrators). Its job is neither to fool the customer nor to falsify the company's image. It is to integrate the customer into the design of the product and to design a systematic process for interaction that will create substance in the relationship."

McKenna makes his points more plausible by using timely examples. For instance, he says the real goal of marketing is to "own the market - not just to make or sell products. It means thinking of your company, your technology, your product in a fresh way."

Apple Computers approached this from two directions. First, by broadening the market. Apple started in a market identified first as "hobby 
computers: dournatofApplied Communications, Vol, 75, Lss,2[1991] Art. 10 arket, McKenna says, Apple identified the "personal computer," which expanded the market concept and made Apple the undeniable market leader.

Later, Apple redefined a market by narrowing its definition. Since IBM owned the business computer market, there was little hope for Apple to squeak out a market share. Instead, Apple created - and owned - a whole new market - desktop publishing. "Once inside the corporate world with desktop publishing, Apple could deepen and broaden its relationships with the business customer."

Technology and marketing once may have looked like opposites, says McKenna, but their marriage has proven otherwise. "Technology permits information to flow in both directions between the customer and the company. It creates the feedback loop that integrates the customer into the company" - and that's what marketing is all about.

Ken Kingsley

Oregon State University

\begin{abstract}
“The Scientific Poster: Guidelines for Effective Visual Communication," by Diane L. Matthews in Technical Communications: Journal of the Society for Technical Communication, Vol. 37, No. 3, (Third Guarter, August 1990). Society for Technical Communication: 815 Fifteenth St. N.W., Washington, D.C. 20005 , pp. 225-232.
\end{abstract}

The scientific poster session is a popular medium for communicating research data at national and international conferences. It often replaces traditional oral presentations or slide presentations. Matthews provides guidelines for producing an effective poster.

The scientific poster requires the integration of research text and graphics for quick visual comprehension. Its major advantage is that it allows the audience to see the material at a reader-selected rate, leading to greater viewer comprehension and retention while the researcher is free to discuss issues, answer questions, distribute handouts, and reinforce highlights. This is not achieved through the traditional "presentation of a paper." Other advantages are that it attracts attention, is informal, can "stand alone" as an active medium or "stand along" as a passive medium. It should be viewed as one large visual entity.

\title{
Textual Considerations
}

Most scientific conferences issue "instructions for posters" or poster guidelines. Traditional spatial limitations are a 4 - $\mathrm{ft}$ by 6 - $\mathrm{ft}$ or 4 -ft by 8 -ft poster area. View poster material from a conceptual standpoint, Matthews suggests. Remember, the audience will spend only minutes reading it.

In planning your poster, underline key points in your presentation and then use only those underlined elements on your poster. Once condensed, "chunk" the information. Chunking means grouping information in conceptual units for the reader. Poster-style lists should be written in phrases 
rather than sentences. Support the lists with icons. They reinforce the text and leave a lasting impression. In the scientific poster, numbers should be numerals rather than spelled out; use \% instead of percent.

You still must use the IMRAD format - Introduction, Methods, Results and Discussion:

- Introduction: a few brief sentences

- Method: a list or a flow chart

- Results: illustrations, tables, figures, graphs accompanied by a simple statement

- Discussion: a list or summary paragraph of conclusions

A stylistically consistent poster exudes professionalism. On the other hand, a sloppy poster implies sloppy research.

Typography - In choosing a font, consider that the typeface creates a feeling. Choose a font that attracts attention and invites the audience to read. Serif fonts, such as Times Roman, Century, and Palatino, are traditional fonts. The serif "feet" direct eye movement for efficient reading. Sans serif fonts, such as Geneva and Helvetica, are contemporary with a straight or clean image. For short segments of text, either type of font is effective. One common practice in design is to use a sans seriffont for titles and a serif font for text.

Title - Poster titles can be effective in all caps, but they should be no more than eight words.

Headings - be consistent regarding whether your headings are all caps, initial caps, boldface, underlined, aligned flush left, or centered. Major headings should not exceed three words; otherwise, they lose impact. Remaining text should be upper and lower case. Headings and listed items should be grammatically parallel. Use active verbs. Active verbs, gerunds, and imperatives are more effective because they imply action.

Text - Be consistent. Paragraphs should be either indented or flush left, but do not mix both styles. All margins should be consistent (top, bottom, right, and left) in all poster elements. Wider margins (preferably 1 inch), are visually appealing because they frame the material with white space, making the text appear more valuable. Precise and consistent margin widths tie the poster elements into a sequence of rhythmically related impressions. Decide whether margins will be justified or ragged right. Justified margins give a neat appearance but cause irregular spacing problems (rivers of white) within the text. Ragged right text provides a certain amount of contrast that leads to greater reading and viewing ease.

\section{Graphic Design}

The scientific poster is effective in communicating research because communication and understanding are accomplished largely through visualization. Graphics are tools that give meaning to information because they show relationships, trends, and comparisons.

Graphs - Graphs show relationships among numerical values in clear, accurate, and effective pictoral form. Guidelines for graphs include the following:

- Bar graphs or histograms should have separated bars of the same width.

- Line graphs should be limited to 3 or 4 lines, each thicker than axis lines. 


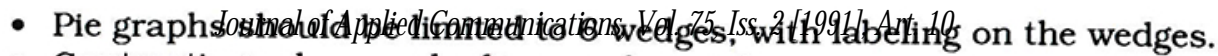

- Contrasting colors or shading can be used.

- Graphical information should not be duplicated in the text.

- Graphics should contain only one message.

Tables - Table guidelines include the following:

- Column headings should be singular, not plural in form.

- Rules should be horizontal, not vertical.

- Decimal points should be aligned.

\section{Visual Perception}

The arrangement of elements, typography, design, and color all contribute to visual appeal and effectiveness.

Arrangement - In Western culture, people begin reading at the upper left corner and then move from left to right horizontally. The information flow in a scientific poster should be vertical or horizontal, but not both. Otherwise, the reader may get confused and move on to another poster. If you must mix directional flows, put a large sequential number in the corner of each element.

The poster window area draws initial eye contact. The window area, or golden rectangle, is the rectangular area in the visual center of the poster area. Key points of research or results expressed in graphs, photos, tables or figures can be highlighted by placing those components in the "window" of the poster with supportive text arranged outside the window area.

Color - Color can be effective, but its overuse can detract from the overall poster effect. Color attracts attention, produces psychological effects, develops associations, builds retention, and creates an aesthetically pleasing atmosphere. Before poster production, choose the poster mat color and a contrasting color for trim tape to frame each poster element. Color can be used in bar graphs, flow charts, or diagrams. The misuse of color is worse than no color at all.

The poster mat board should have a consistent frame around each pinup element. Trim tape that frames each poster element, coordinates and complements the scientific poster, adding a neat appearance.

One color plus black offers the greatest contrast because a color is always its most intense with black. Warm colors (such as red, orange, and yellow) are higher in visibility than cool colors. However, for an attractive scientific poster, keep the use of warm, vibrant colors to a minimum. Bright colors detract from the significance of the scientific data being presented.

\section{Other Consideration}

Handouts - They are an important component of a successful poster session. Handouts should present a condensed version of the poster with summary statements, tables and graphs, or a reproduction of the entire presentation in the form of a model page. If background material is vital to the presentation, include it in the handout. References or bibliographical information belong in the handout.

Types of Posters - Many factors determine poster style - instructions from conference coordinators, available finances, transportation, and means of production. Four poster presentation styles are common:

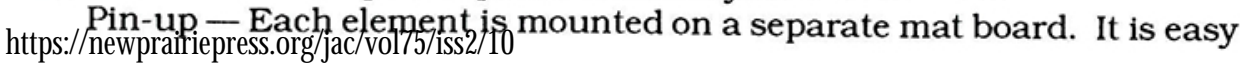


Knebusch et al.: Why Trades Get No Respect; Defending the Editorial Budget; What

to transport. Production time is increased because a mat board must be cut to specification for each element, and all margins must be consistent between elements.

Stand-alone tabletop - It may consist of three 2-ft x 4-ft panels connected at the back so it can be folded for easy transport.

Floor-standing - This requires expensive materials and special transport.

Roll-up - This is produced on a 4- $\mathrm{ft}$ x 6-ft (or 8-ft) paper and laminated. It rolls up for transport and is pinned onto a cork board or other surface provided at the conference.

Scientific posters must meet a high professional standard, not just for ease of reading and comprehension, but also because the impression they create is often extended to the quality of the research. If you are preparing a scientific poster, Matthews" article with its 10 illustrations is "must" reading. Or, if you want to know more about this medium of the '90s, which may be replacing the traditional paper and slide-tape presentations at scientific meetings, this is the article.

Carol Sanders Reiner University of Arkansas- Little Rock

\section{"Editing and Publication: A Training Manual" by Ian Montagnes Manila, Philippines: International Rice Research Institute and Ottawa: International Development Research Centre. 1991. (Order from IRRI: US\$7 for developing countries; US\$32 for developed. Postage: US\$11 for airmail; US\$3 for surface.)}

The International Rice Research Institute (IRRI), which has taught rice technology to many thousands of Third-World workers, widened its training responsibility to include editors. Tom Hargrove, IRRI information head, was the motivator. Canada's International Development Research Centre was the co-sponsor and donor. Canada made another big contribution: veteran University of Toronto Press editor Ian Montagnes created and taught the courses. And out of that program came two books just published by IRRI. One, a 492-page opus, is the subject of this review. The other is a shorter handbook for trainers of editors. They were brought out especially for Third World use-as you'll see in the price differentials. But consider their content and value before the question of price!

This is, by far, the most complete work we've seen on its subject. Organizing it into 84 lessons, Montagnes discusses- understandably in all cases and interestingly in most-about everything under the purview of editor. He cites, for instance, 20 "different tasks" of an editor. He explores to useful depth the often-undefined relationships of author, editor, and reader.

"Good editors always have two people in mind: the author and the intended reader," he suggests. The editor asks at every stage: "What did the author intend? Have I understood the author clearly? Will the reader understand this? What can I do to make the manuscript easier? Will the reader want to read it?" I applaud his detailed treatment of "knowing the reader," which I see as maybe the most neglected part of an editor's job. He's

Published by N ew Prairie Press 2017 of Applied Communications, Vol. 75, No. 2, 1991/65 


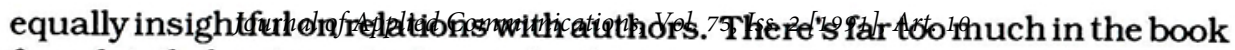
for a detailed review. Just consider the 11 principal topics: 1 . Author, editor, reader; 2 . Getting the most of out words; 3 . The editor's many tasks; 4 . Editing for the specialist; 5. Reaching the nonspecialist; 6 . Illustrations; 7. Design the publication; 8. Introduction to print production; 9. Production management; 10 . The business side; 11 . Reaching the reader. Eighty-four lessons (range from 3 to 13 per topic) lay out the material. We've been doing workshops on technical writing and editing in two Third World countries. Sadly, this work wasn't on the shelf when we started. But it will be with the classes from now. We won't try to teach it all, but it will be strong support for what we do. But, in our opinion, it's not a self-teacher, especially for Third-World editors. For a First-World editor, it can be a good resource: at minimum, it's a great reminder; many will find it to be a well-focused guide for the working editor.

K. Robert Kern Communication for Agriculture World-Wide 